Article

\title{
Ground Deformation Pattern Analysis and Evolution Prediction of Shanghai Pudong International Airport Based on PSI Long Time Series Observations
}

\author{
Xin Bao ${ }^{1}$, Rui Zhang ${ }^{1,2, * \mathbb{C}}$, Age Shama ${ }^{1}$, Song $\mathrm{Li}^{1}{ }^{1}$, Lingxiao Xie ${ }^{1}$, Jichao Lv ${ }^{1} \mathbb{D}$, Yin Fu ${ }^{1}$, Renzhe Wu ${ }^{1} \mathbb{D}$ \\ and Guoxiang Liu ${ }^{1,2}$ \\ 1 Faculty of Geosciences and Environmental Engineering, Southwest Jiaotong University, \\ Chengdu 610031, China; baoxin@my.swjtu.edu.cn (X.B.); shamaage@my.swjtu.edu.cn (A.S.); \\ lisong123@my.swjtu.edu.cn (S.L.); lingxiao@my.swjtu.edu.cn (L.X.); lvjichao@my.swjtu.edu.cn (J.L.); \\ rsyinfu@my.swjtu.edu.cn (Y.F.); mrwurenzhe@my.swjtu.edu.cn (R.W.); rsgxliu@swjtu.edu.cn (G.L.) \\ 2 State-Province Joint Engineering Laboratory of Spatial Information Technology of High-Speed Rail Safety, \\ Southwest Jiaotong University, Chengdu 610031, China \\ * Correspondence: zhangrui@swjtu.edu.cn
}

check for updates

Citation: Bao, X.; Zhang, R.; Shama, A.; Li, S.; Xie, L.; Lv, J.; Fu, Y.; Wu, R.; Liu, G. Ground Deformation Pattern Analysis and Evolution Prediction of Shanghai Pudong International Airport Based on PSI Long Time Series Observations. Remote Sens. 2022, 14, 610. https://doi.org/ $10.3390 /$ rs 14030610

Academic Editors: Zhong Lu and Lei Zhang

Received: 23 December 2021

Accepted: 25 January 2022

Published: 27 January 2022

Publisher's Note: MDPI stays neutral with regard to jurisdictional claims in published maps and institutional affiliations.

Copyright: (C) 2022 by the authors. Licensee MDPI, Basel, Switzerland. This article is an open access article distributed under the terms and conditions of the Creative Commons Attribution (CC BY) license (https:// creativecommons.org/licenses/by/ $4.0 /)$.

\begin{abstract}
Being built on the reclamation area, Shanghai Pudong International Airport (SPIA) has been undergoing uneven subsidence since the beginning of its operation in 1999. In order to explore the evolution characteristics of ground deformation in the SPIA reclamation area and further provide assurance for the airport's safe operation, 141 Sentinel-1A images from October 2016 to September 2021 were selected to acquire time-series ground deformation observations by the StaMPS PSI processing procedure. We subsequently built a ground deformation prediction model using the Long Short Term Memory (LSTM) neural network for the short-term prediction of the SPIA deformation severity area. On this basis, the spatial-temporal evolution trends of SPIA ground deformation in the reclamation area were revealed concerning the influence and mode of action of geological conditions and environmental factors. Finally, we proposed targeted recommendations and strategies for the comprehensive ground deformation prevention and control needs of SPIA. The results indicated that the SPIA exhibits overall subsidence in the eastern part, with the maximum deformation rate reaching $-57.29 \mathrm{~mm} / \mathrm{a}$. Meanwhile, the central and western part has a local uplift with the maximum deformation rate reaching $32.76 \mathrm{~mm} / \mathrm{a}$. The proposed LSTM ground deformation prediction model demonstrated excellent robustness in the region of uneven deformation, and the prediction results were in high agreement with the StaMPS PSI monitoring results. The time-series observations and prediction results are expected to provide references for the expansion project of SPIA and help the research of ground deformation and prevention in related fields.
\end{abstract}

Keywords: Shanghai Pudong International Airport; reclamation area; InSAR; LSTM; deformation evolution prediction; prevention and control strategies

\section{Introduction}

With the rapid socio-economic development, many coastal cities have resorted to reclamation to alleviate the shortage of land for urban construction and transportation [1-3]. To implement the city planning rationally and reduce the pressure of air transportation, most of the coastal cities built their airports near the sea and far from the downtown area, such as Hong Kong International Airport [4], Macau International Airport [5], Shanghai Pudong International Airport [6], etc. These airports will inevitably have ground deformation problems, especially uneven deformation, due to the short period of land reclamation and weak natural foundations, which pose a significant safety hazard [7]. Therefore, it is essential to grasp the ground deformation of airports in reclamation areas in time and propose corresponding prevention and control strategies for safe airport operation. 
Traditional methods of ground deformation monitoring in the airport are mainly based on ground instrument measurements at some point targets, such as Global Positioning System (GPS) and leveling. It has disadvantages including its time-consuming nature and difficulty in clearly showing the macro-spatial distribution of ground deformation, especially for massive infrastructure with large areas and long spans, such as buildings, roads, bridges, etc. The disadvantages are particularly obvious. With the rise of Interferometric Synthetic Aperture Radar (InSAR) technology, it enables large-area ground deformation monitoring with higher spatial resolution and subcentimeter accuracy, breaking through the limitations of traditional methods $[4,8,9]$. However, the InSAR technique is susceptible to decorrelation, atmospheric artifacts, and orbital errors [10]. Therefore, the Time Series InSAR (TS-InSAR) technique was proposed to explore the spatial-temporal characteristics of the ground deformation in detail [11-13]. In 2004, Hooper et al. proposed the Stanford Method for Persistent Scatterers (StaMPS) technique, which further improves the spatial resolution of observation points through interference phase and amplitude statistics [14]. Moreover, the high-resolution observations acquired help improve the monitoring capability in the decorrelation area [15].

In recent years, TS-InSAR technology has been imported into the ground deformation monitoring in reclamation airports [16,17]. Miao et al. extracted spatial and temporal deformation information from 2007 to 2010 at Shenzhen Baoan International Airport, China, using an improved Persistent Scatterer Interferometry (PSI) technique. The results showed that uneven subsidence was observed in the newly reclaimed area of the airport [18]. Zhao et al. used the PSI technique and Envisat satellite data to obtain the ground deformation of Hong Kong International Airport from 19 April 2006 to 9 January 2008 [19]. Jiang et al. used an improved PSI technique to invert the mean deformation rate and SPIA ground deformation; they performed time-series deformation analysis using the high-resolution TerraSAR-X satellite imagery acquired from September 2011 to October 2012 [6]. Yu et al. used X-band TerraSAR-X (TSX) and TanDEM-X (TDX) data to extract ground deformation information for SPIA from December 2009 to December 2010 and from April 2013 to July 2015. The time-series analysis showed that the SPIA experienced significant ground subsidence, with cumulative deformation reaching $-30 \mathrm{~mm}$ and $-35 \mathrm{~mm}$, respectively [7]. Although previous research extracted information on airport deformation in reclaimed areas, it is challenging to explore the deformation evolution trend model and reveal the relationships between the ground deformation and various geological and environmental factors. In addition, most of the relevant studies for SPIA were performed before 2017, and recent results are lacking.

With the rapid development of the above-mentioned TS-InSAR technology in reclamation airports' ground deformation, monitoring data characterized by dense time series are becoming more and more available, making it possible to predict the ground deformation of reclamation airports. The prediction methods include three main categories: mathematical and statistical models, empirical models, and traditional artificial neural network models [20-23]. However, the applicability potential of these conventional methods is often limited by a priori knowledge. Moreover, the obtained prediction results are unreliable due to the lack of prior model parameters or relevant data [24,25]. In contrast, the Long Short Term Memory (LSTM) neural network can efficiently and accurately predict time series data by considering historical data's nonlinearity and time dependence and showing excellent performance in ground deformation prediction $[23,24]$.

For revealing the ground deformation evolution characteristics of the SPIA reclamation area in recent years, this paper carried out the prediction of deformation evolution and subsidence pattern analysis of SPIA by the long time-series ground deformation observations acquired with the StaMPS PSI. This article is organized as follows. Section 2 presents the study area and datasets. Section 3 describes the methods involved in ground deformation monitoring and LSTM prediction models. Section 4 offers the ground deformation monitoring results and accuracy verification. Section 5 demonstrates the performance of the LSTM prediction model and proposes a ground deformation prevention and control 
scheme in the context of geological and environmental effects on ground deformation. The conclusions are drawn in Section 6.

\section{Study Area and Datasets}

\subsection{SPIA and Its Reclamation History}

The SPIA is located in the coastal area of Zhuqiao Town, Pudong New District, Shanghai, China, about $30 \mathrm{~km}$ from the downtown area. The majority of SPIA is built on reclaimed land with a total area of approximately 824,000 square meters (Figure 1a). As one of three major international airports in China, this airport had a passenger throughput of 74,006,300 and 3,768,600 tons of cargo and mail in 2018 [26]. As shown in Figure 1b,c, SPIA has been included in the municipal planning of Shanghai since 1986 [27]. After completing the Phase I project (mainly the Terminal T1 and a runway), the airport was put into operation in 1999 [27]. The design process of the SPIA Phase II project was completed in 2006, followed by the expansion of Terminal T2, Runway 3, Runway 4, Runway 5, and the world's largest single-satellite hall, gradually forming the scale of today [28]. Most runways and infrastructure were constructed on foundations from different periods, leading to uneven ground deformation in subsequent years. Therefore, it is essential to research ground deformation monitoring and the evolution pattern of SPIA for the overall stability assessment and safe operation of the airport.
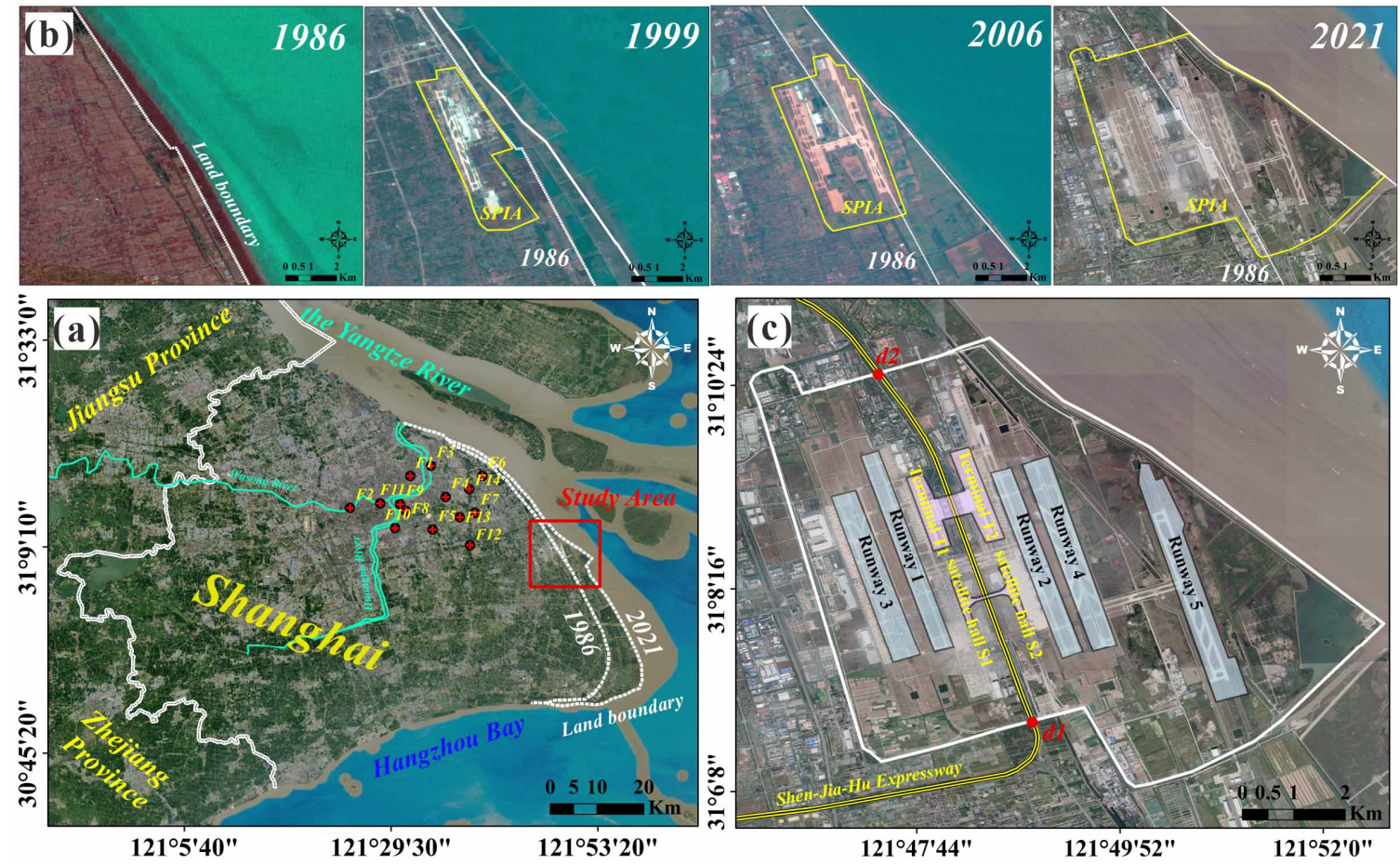

Figure 1. Google Earth-based maps of (a) Shanghai city and the study area; (b) spatial evolution of land reclamation in Shanghai Pudong International Airport (SPIA) since 1986; and (c) a sketch map of the SPIA. F1 to F14 represent the leveling points; d1 and d2 represent the two endpoint locations of the Shen-Jia-Hu Expressway at the SPIA.

\subsection{Datasets}

The data of Sentinel-1A from January 2016 to September 2021 were collected for measuring the ground deformation of SPIA. The SPIA has been expanding over the past years. The time-series dataset was divided into five groups (S1 to S5) to reduce the decorrelation and atmospheric delay. In addition to using leveling-point data (F1 to F14 shown in Figure 1a [29]) to validate the StaMPS PSI results, repeated data were set up between every adjacent group for cross-validation, as outlined in Table 1. ESA's precise orbit determination (POD) was imported to remove the orbit error, and the topographic phase components 
were removed from the interferograms with Shuttle Radar Topography Mission (SRTM) 1 $\operatorname{arc}-\sec (30 \mathrm{~m})$ data. The acquisition dates of the images are indicated in Figure 2.

Table 1. Basic parameters of Sentinel-1A images.

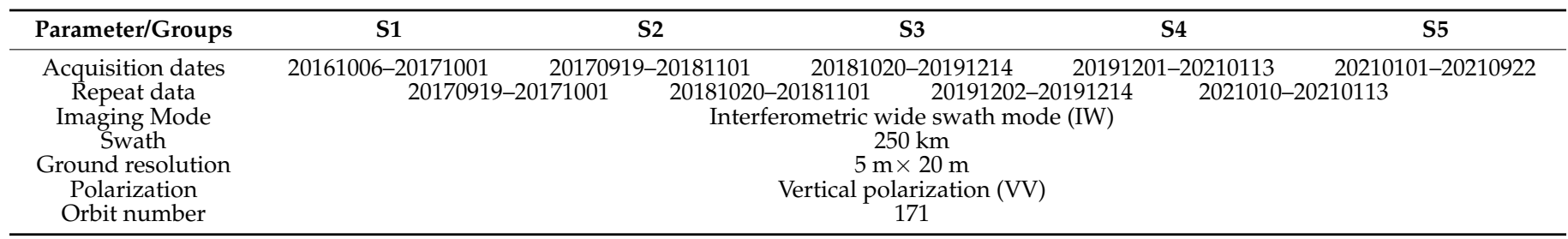

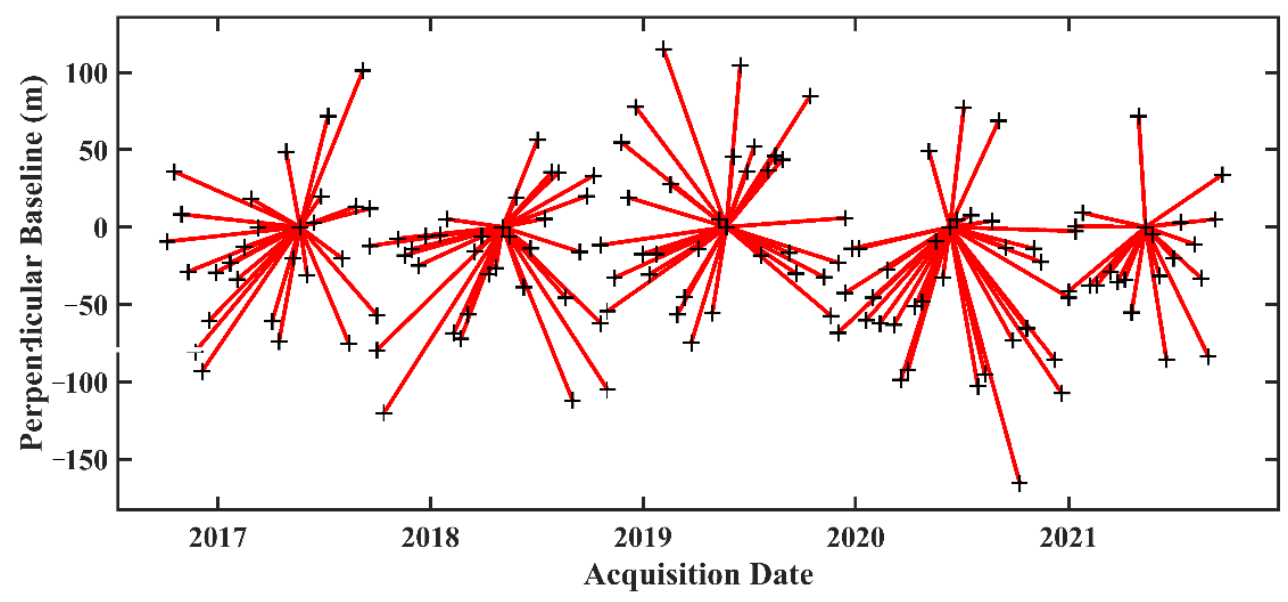

Figure 2. Acquisition dates and perpendicular baselines of SAR data.

\section{Methodology}

The StaMPS PSI technique was applied to process Sentinel-1A data and determine the ground deformation of the time series InSAR for SPIA from 2016 to 2021. Then based on StaMPS PSI observations, an LSTM neural network was established and applied to predict the ground deformation. Finally, we proposed recommendations and strategies for SPIA ground deformation prevention and control. The method flow is shown in Figure 3.

\subsection{StaMPS PSI}

This Persistent Scatterer (PS) points selection is based on a spatial correlation of interferometric phase and amplitude dispersion, which is the critical principle of StaMPS PSI. In contrast, other PSI approaches identify PS using a functional model of ground deformation fluctuating with time [14]. Assume $N$ interferograms are created from $N+1$ SAR images obtained on the same track and in the same study area for one master image at various epochs. The master image we chose should take into account the temporal and spatial baselines and the effect of the Doppler central frequency [30,31]. We initially chose the PS candidates using a delta amplitude dispersion threshold of 0.4 .

The amplitude dispersion index $D_{A}$ value is used to filter non-PS candidate pixels. The amplitude dispersion index is denoted as [32]

$$
D_{A}=\frac{\sigma_{A}}{\mu_{A}}
$$

where $\sigma_{A}$ and $\mu_{A}$ are the standard deviation and mean of the amplitude values, respectively. The phase stability of each candidate PS pixel was estimated after a subset of PS candidates was chosen. The differential interference phase wrapped by one PS pixel X can be characterized as follows [31]: 


$$
\varphi_{x, i}=W\left\{\phi_{\mathrm{def}, x, i}+\phi_{\mathrm{atmp}, x, i}+\Delta \phi_{S, x, i}+\Delta \phi_{\theta, x, i}+\phi_{N, x, i}\right\}
$$

where $W\{$.$\} is the wrapping operator; \phi_{\text {def }, x, i}$ is the phase change caused by surface movement in the line-of-sight (LOS) direction and is vital for deformation analysis. $\phi_{\text {atmp }, x, i}$ and $\Delta \phi_{S, x, i}$ are the atmospheric delay component and the residual phase component caused by inaccurate satellite orbits, respectively. $\Delta \phi_{\theta, x, i}$ represents the phase component due to look angle inaccuracy, while $\phi_{N, x, i}$ represents the noise generated by scattering effects.

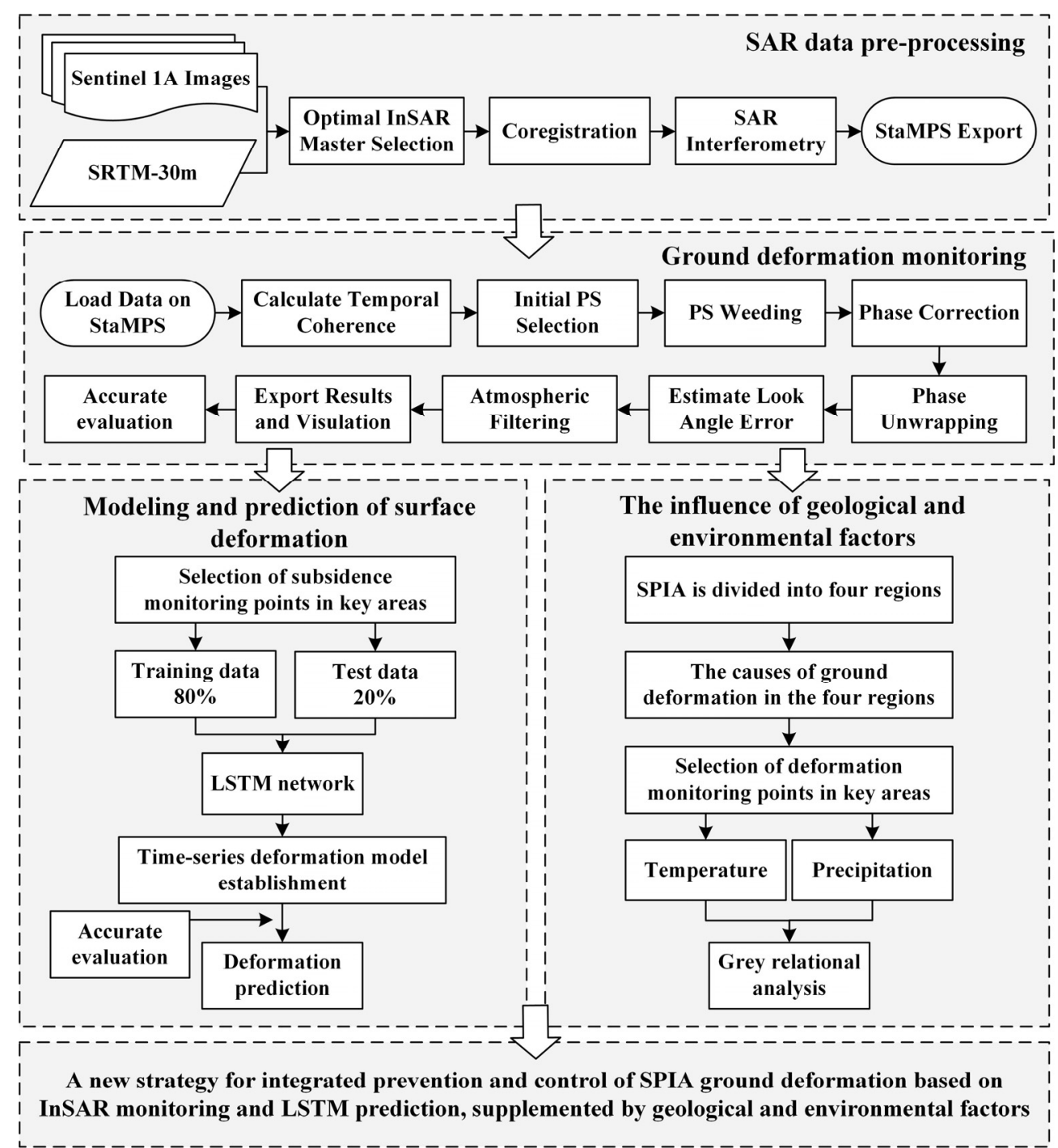

Figure 3. The overall technical flow chart.

Equation (3) can be used to check the phase stability of the remaining pixels [33].

$$
\gamma_{X}=\frac{1}{N}\left|\sum_{i=1}^{N} \exp \left\{\sqrt{-1\left(\varphi_{x i}-\widetilde{\varphi}_{x i}-\Delta \hat{\phi}_{\theta_{\theta x}}^{u}\right)}\right\}\right|
$$

$N$ represents the number of interferograms, $\varphi_{x i}$ represents the wrapped phase, $\widetilde{\varphi}_{x i}$ represents the wrapper estimate of the spatially relevant part of $\varphi_{x i}$, and $\Delta \hat{\phi}_{\theta_{\theta x}}^{u}$ is the error phase. PS pixels are selected from pixels that meet the desired convergence rate. The DEM errors are estimated and removed using the selected PS points. After phase unwinding and high and low pass filtering, the final deformation is obtained. 


\subsection{Long Short Term Memory Neural Network}

In recent years, deep learning as a new machine learning method has received much attention from many industries [23,34-36]. LSTM was proposed by Hochreiter and Schmidhuber in 1997 [37]. It is a recurrent neural network (RNN) architecture designed to cope with serial data, so it has a unique advantage in learning the features of time series data. Figure 4 shows the basic structure of the LSTM model [23].

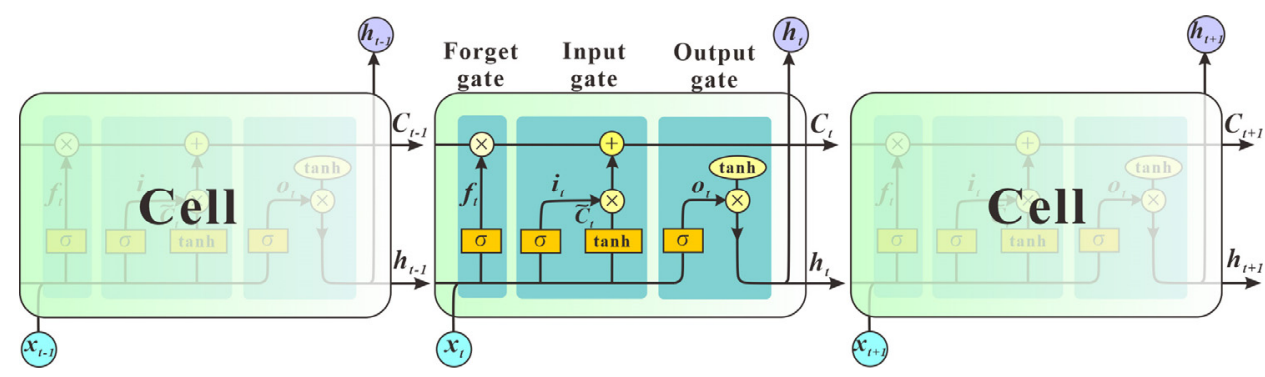

Figure 4. The basic computational unit of the LSTM model.

The first step of the LSTM relies on a sigmoid layer called the "forget gate layer" to decide what information to retain from the cell state. When the data entered are essential, the "forget gate layer" chooses to forget the previously entered data and keeps the current data. Equation (4) is the calculation method for the forget gate.

$$
f_{t}=\sigma\left(W_{t}\left[h_{t-1}, x_{t}\right]+b_{f}\right)
$$

where $f_{t}$ represents the forget gate and ranges from 0 to $1 ; \sigma$ represents the sigmoid function; $W_{t}$ and $b_{f}$ indicate the forget gate's weight vector and offset, respectively. The output of the LSTM network at the $t-1$ layer is represented by $h_{t-1}$, and $x_{t}$ represents the input vector.

The next step needs to be divided into two parts to decide what new information needs to be stored in the cell state. First, the sigmoid layer decides which values we want to update. Then, the tanh layer generates a vector of new candidate values $\widetilde{C}_{t}$, which can be added to the state. The following equation can express the input gate.

$$
\begin{gathered}
i_{t}=\sigma\left(W_{i}\left[h_{t-1}, x_{t}\right]+b_{i}\right) \\
\widetilde{C}_{t}=\tanh \left(W_{C}\left[h_{t-1}, x_{t}\right]+b_{C}\right)
\end{gathered}
$$

where $i_{t}$ is the input gate, $W_{i}$ is the input gate weight vector, $b_{i}$ is the input gate deviation vector, $W_{C}$ represents the weights used for updating, and $b_{C}$ represents the deviation [23]. The current state of the network layer, determined by both the input gate and the forget gate, is calculated as follows.

$$
C_{t}=f_{i} * C_{t-1}+i_{t} * \widetilde{C}_{t}
$$

Finally, the output gate decides whether or not to output the current state and what information is available for output.

$$
\begin{gathered}
o_{t}=\sigma\left(W_{o}\left[h_{t-1}, x_{t}\right]+b_{o}\right) \\
h_{t}=o_{t} * \tanh \left(C_{t}\right)
\end{gathered}
$$

where $o_{t}$ and $h_{t}$ represent the output gate and the new output value, respectively. $W_{o}$ is the weight vector of the output gate and $b_{o}$ is the deviation vector. 
The Root Mean Square Error (RMSE) was used to evaluate the accuracy of the LSTM neural network.

$$
R M S E=\sqrt{\frac{1}{M} \sum_{t=1}^{M}\left(y_{t}-\hat{y}_{t}\right)^{2}}
$$

where $y_{t}$ and $\hat{y}_{t}$ are the ground deformation observations and LSTM predictions at time $\mathrm{t}$, respectively, and $M$ is the number of training and test datasets.

\section{Results}

\subsection{Spatial Distribution of Deformation}

Figure 5 shows the average deformation rate of SPIA obtained from the SAR data from groups S1 to S5. Negative values in the graph indicate ground subsidence, while positive values indicate ground uplift. As shown in Figure 5, there was an overall uneven deformation of SPIA, with the average deformation rate varying between $-57 \mathrm{~mm} / \mathrm{a}$ and $33 \mathrm{~mm} / \mathrm{a}$. Ground deformation is most severe in the eastern part of SPIA, especially in the area near the offshore and in the vicinity of Runway 5, where subsidence rates ranged from $-57 \mathrm{~mm} / \mathrm{a}$ to $20 \mathrm{~mm} / \mathrm{a}$. In the central and western parts of SPIA, local ground uplift occurs especially in Terminal T1 and Terminal T2 and along the Shenjiahu Expressway, with a maximum deformation rate of about $33 \mathrm{~mm} / \mathrm{a}$. Comparatively speaking, the ground deformation is relatively minor in the areas adjacent to Runway 1 and 3, as well as Runway 2 and 4, respectively. In addition, the distribution of PS points obtained in the study area was not uniform, and the density of PS points in offshore regions was lower than inland areas. This unevenly distributed spatial pattern is primarily attributed to the different soil consolidation stages in the reclamation area [38].

\subsection{Accuracy Validation}

The ground leveling point measurements from October 2016 to October 2017 were imported to comprehensively evaluate the accuracy of ground deformation in the study area using the StaMPS PSI technique. The location and number of the leveling points are shown in Figure 1a. Figure 6 shows the comparison results of the annual average deformation rate of the observation points extracted by leveling measurement and the StaMPS PSI technique. The RMSE of the two methods was $1.19 \mathrm{~mm} / \mathrm{a}$, and the comparison results did not differ by more than $3 \mathrm{~mm} / \mathrm{a}$. Therefore, the monitoring results of the StaMPS PSI technique keep the excellent agreement with the leveling measurements.

There are some missing leveling data due to the long observation period. Therefore, we used the cross-validation method to evaluate the quality of ground deformation results for other periods during which leveling results are not available [39]. The ground deformation results were resampled to reduce the effect of geographic offset. The Shenjiahu Expressway section $\mathrm{d} 1$ to $\mathrm{d} 2$ within the SPIA was relatively stable between 2016 and 2021 (see Figure 1c) and had many PS points. So, the cumulative deformation of the repeated SAR data sets in the two groups of experiments was calculated along sections $\mathrm{d} 1$ to $\mathrm{d} 2$ (see Table 1 ). Then, their coefficients of determination were derived. Figure 7 shows the comparative results of the accumulated deformation of the four experimental groups. The coefficients of determination were $0.89,0.97,0.98$, and 0.87 , respectively, indicating good reliability of the experimental results.

As shown in Figure 5a, the deformation of Runway 1 and Runway 3 stabilized from 2016 to 2017, and the deformation rate remained around $5 \mathrm{~mm} / \mathrm{a}$, which is consistent with the solution of Yu et al. [40]. In addition, Jiang et al. [6] and Yu et al. [7] obtained SPIA ground deformation results before 2016 using PSI and SBAS techniques, respectively. Both results showed a large deformation gradient of SPIA in the east-west direction. The deformation of SPIA showed the same spatial distribution during the period studied in this paper (2016 to 2021). With the completion of the Phase III expansion, the deformation of the east side of SPIA against the sea increased. Figure 8 shows the ground fractures within 
the SPIA due to ground deformation. Therefore, the inhomogeneous deformation of the ground creates potential severe problems for the safe operation of SPIA [41].
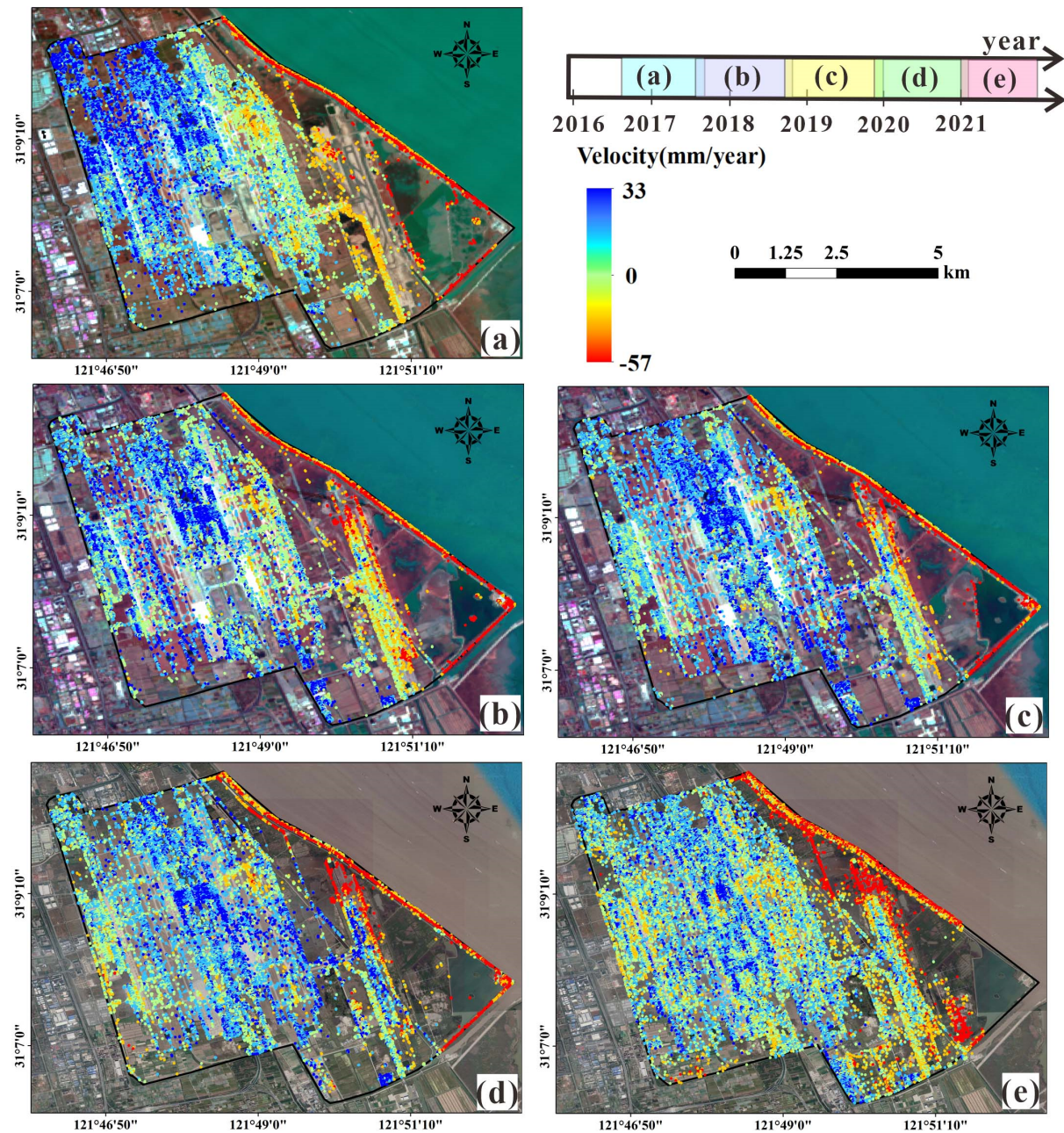

Figure 5. LOS deformation velocity maps estimated from (a) S1:2016.10-2017.10; (b) S2:2017.092018.11; (c) S3:2018.10-2019.12; (d) S4:2019.12-2021.01; (e) S5:2021.01-2021.10 (Background image: Google Maps satellite image).

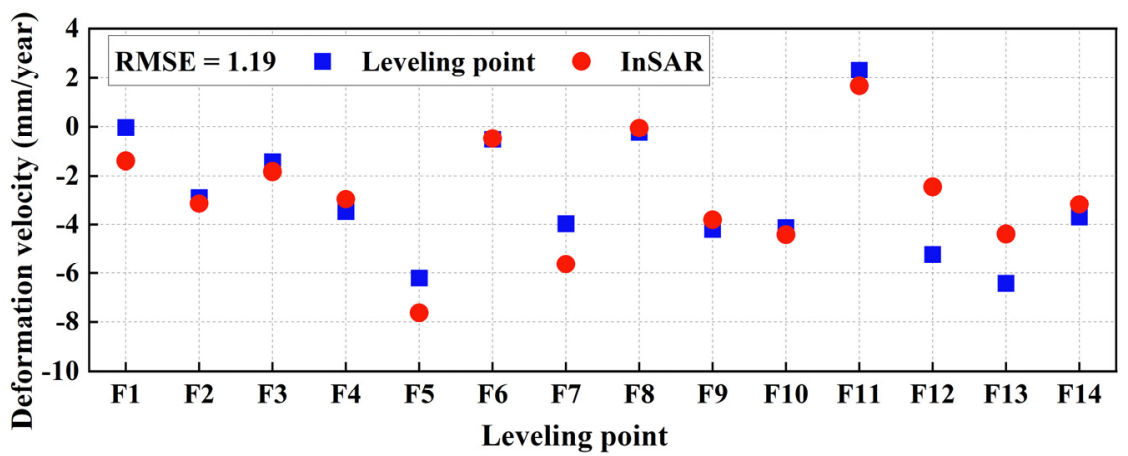

Figure 6. Comparison of deformation rate monitoring by leveling and InSAR. 

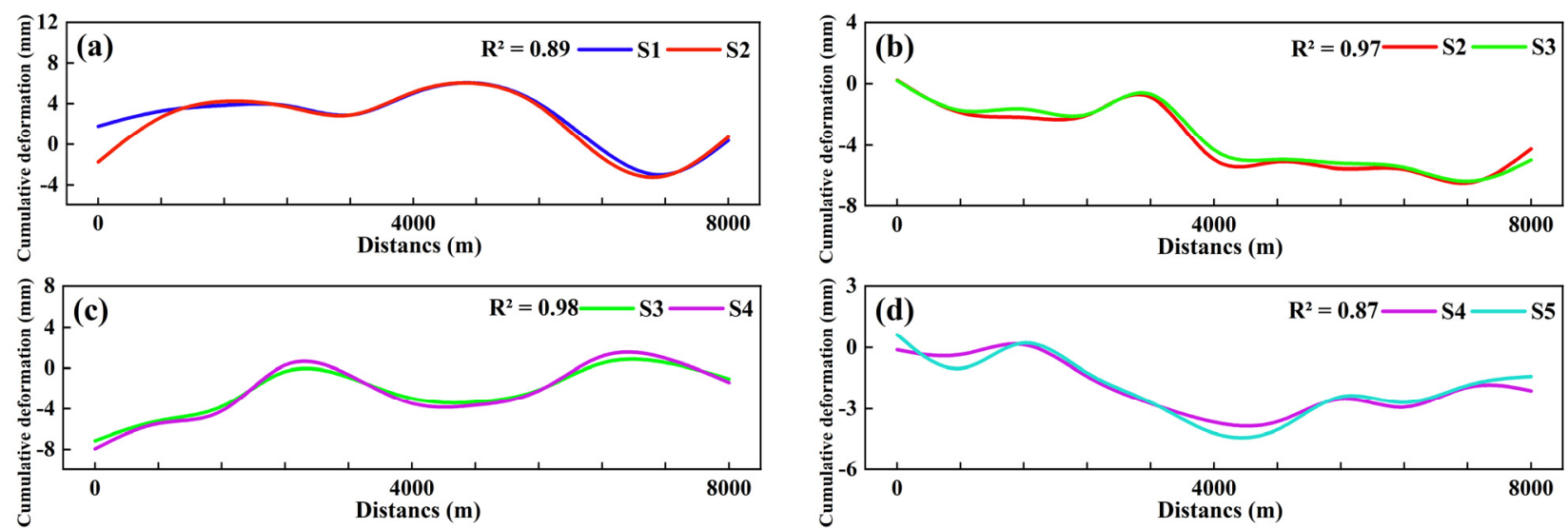

Figure 7. Cumulative deformation results of repeated SAR data for (a) groups S1 and S2; (b) groups S2 and S3; (c) groups S3 and S4; (d) groups S4 and S5.
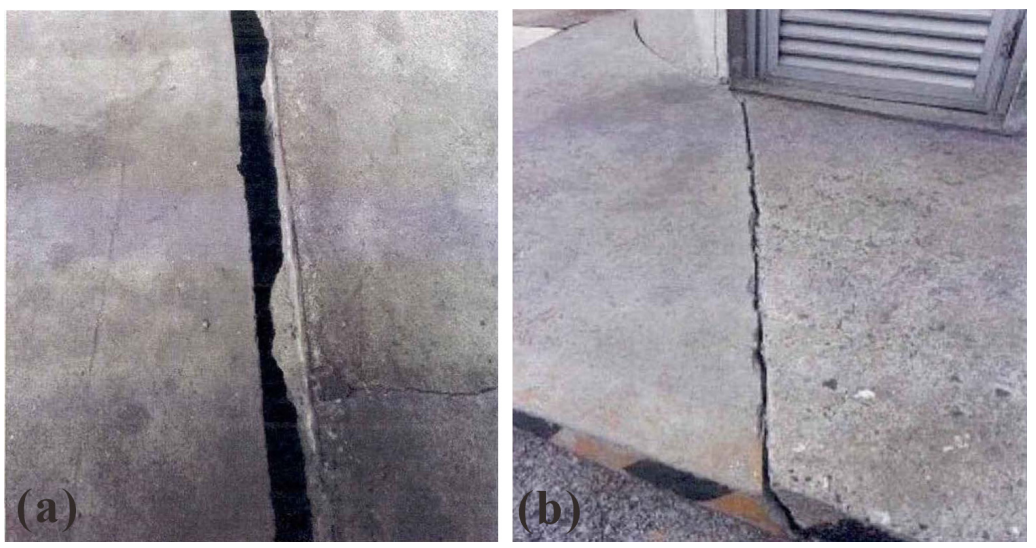

Figure 8. Ground fractures from ground deformation, (a) cracks on the transition zone in front of Terminal 1; (b) crack at the boarding bridge of Terminal 2.

\section{Discussion}

\subsection{SPIA Ground Deformation Prediction}

The areas M1, M2, and M3 within SPIA with the most severe ground subsidence were focused on in this study. Based on Python 3.6 language and the Tensorflow 2.0 deep learning framework, a LSTM neural network was utilized to build a ground deformation prediction model $[23,25]$. The adaptive moment estimation (ADAM) algorithm was chosen as the optimizer. This algorithm can calculate the adaptive learning rate for different parameters and consumes fewer storage resources. Compared with other stochastic optimization methods, the ADAM algorithm performs better in practical applications [42]. The grid search algorithm was applied to select the hyperparameters in the LSTM ground deformation prediction model. The optimization objective minimizes the MSE loss function, given the network layers (K), hidden layer nodes (S), and epoch. The maximum number of network layers $\left(K_{\max }\right)$ and hidden layer nodes $\left(\mathrm{S}_{\max }\right)$ in the grid search need to be set empirically by humans based on the prediction effect [25]. According to the actual training situation, $K_{\max }$ and $S_{\max }$, set to 5 and 30 in this paper, respectively, are sufficient to find the optimal parameters. So $K \in[1,2,3,4,5], S \in[1,2, \cdots, 30]$ is used for the experiment. The optimal number of network layers and hidden layer nodes were determined to be 3 and 12, respectively, after experiments with the combination of several parameters. As shown in Figure 9, the RMSE was minimized when the epochs reached 400. Therefore, the optimal hyperparameters of the LSTM ground deformation prediction model were experimentally derived, as shown in Table 2. 


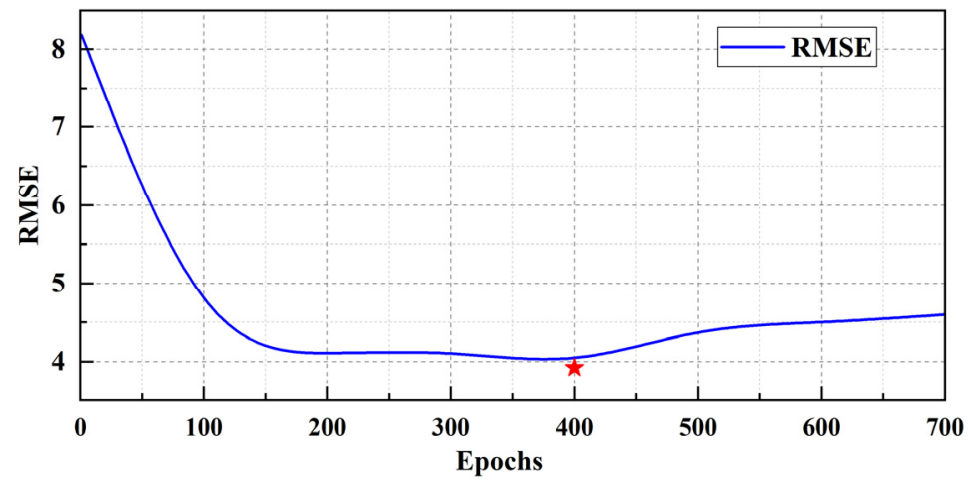

Figure 9. Relationship between RMSE and epochs.

Table 2. Optimal search results for hyperparameter combinations.

\begin{tabular}{cccccccc}
\hline $\begin{array}{c}\text { Hyper } \\
\text { Parameter }\end{array}$ & $\begin{array}{c}\text { Training } \\
\text { Data }\end{array}$ & Testing Data & $\begin{array}{c}\text { Layers of } \\
\text { LSTM }\end{array}$ & $\begin{array}{c}\text { Nodes in the } \\
\text { Hidden Layer }\end{array}$ & $\begin{array}{c}\text { Optimizer } \\
\text { Ware }\end{array}$ & $\begin{array}{c}\text { Loss } \\
\text { Function }\end{array}$ & Epochs \\
\hline Value setting & $70 \%$ & $30 \%$ & 3 & 12 & ADAM & MSE & 200 \\
\hline
\end{tabular}

The training and validation process of the LSTM model is shown in Figure 10. Then, the LSTM prediction model was trained and tested; 70\% of the StaMPS PSI ground deformation monitoring data were used for training and 30\% for testing. As shown in Figure 10b-d, the root-mean-square errors of the test data for the areas M1, M2, and M3 were 4.25, 6.18, and 4.50, respectively. The predicted values are in good agreement with the actual values, indicating that the LSTM prediction model developed in this experiment can make valuable and reliable predictions of ground deformation. It is worth noting that current and past settlement rates do not necessarily mean significant future settlement rates. If water table changes more remarkable than the past maximum do not occur, the primary consolidation process terminates after a period, which may take some time but is still finite [43-46]. Therefore, to ensure the reliability of the prediction results, the LSTM model was applied to make short-term predictions for areas with severe ground subsidence within the SPIA. The prediction duration of this experiment was set to six months. The prediction results showed that M3, the area furthest from the coastline, will be stable during the next six months, while M1 and M2 will experience continuous ground subsidence. In particular, the subsidence in M1, which is the closest to the coastline, is severe, and the maximum cumulative subsidence was predicted to reach $-78.21 \mathrm{~mm}$.

\subsection{Correlation Analysis of Ground Deformation with Reclamation Time and Airport Construction}

To better serve the SPIA Phase IV expansion project, the SPIA ground deformation in 2021 and the stage of ground deformation development after the SPIA reclamation project were focused on analysis and discussion. The SPIA was divided into four areas, A, B, C, and D, according to the chronological order of SPIA reclamation construction [38]. As shown in Figure 11a, area A is the land in 1986, and areas B, C, and D are the newly added SPIA land reclamation areas in 1999, 2006, and 2021, respectively.

Once the boundary of each area was determined, the correlation between the reclamation phase and the ground deformation was quantitatively evaluated by calculating the average deformation rate of the four areas, as shown in Figure 11b. The average deformation rate of the PS points describes the primary deformation trend within each area, and the standard deviation illustrates the deformation variation and possible errors in each area. The standard deviation of the average deformation rate gradually increased from area A to area $\mathrm{D}$, indicating that area $\mathrm{D}$ has the most significant spatial variation. The average deformation rate for January through September 2021 was approximately $2.18 \mathrm{~mm} / \mathrm{a}$ in area A, where many roads and buildings cover reclaimed land. In contrast, a slight ground 
uplift of about $0.51 \mathrm{~mm} /$ a was observed in area B, which contains mainly Terminal T2 and most of Runway 2 and Runway 4. Slight subsidence (about $-1.96 \mathrm{~mm} / \mathrm{a}$ ) was observed in area C, with few buildings. A large number of PS points were detected in areas A, B, and $C$. Since reclamation in these three areas has been completed for more than fifteen years, most of the PS points in the three areas exhibited relatively good stability $(-7 \mathrm{~mm} / \mathrm{a}$ to $8 \mathrm{~mm} / \mathrm{a}$ ). Compared with the stable old reclamation area, severe ground subsidence occurred in the reclaimed area D after 2006, with an average deformation rate of about $-16.27 \mathrm{~mm} / \mathrm{a}$, which mainly contains Runway 5 and the emergency rescue training base.
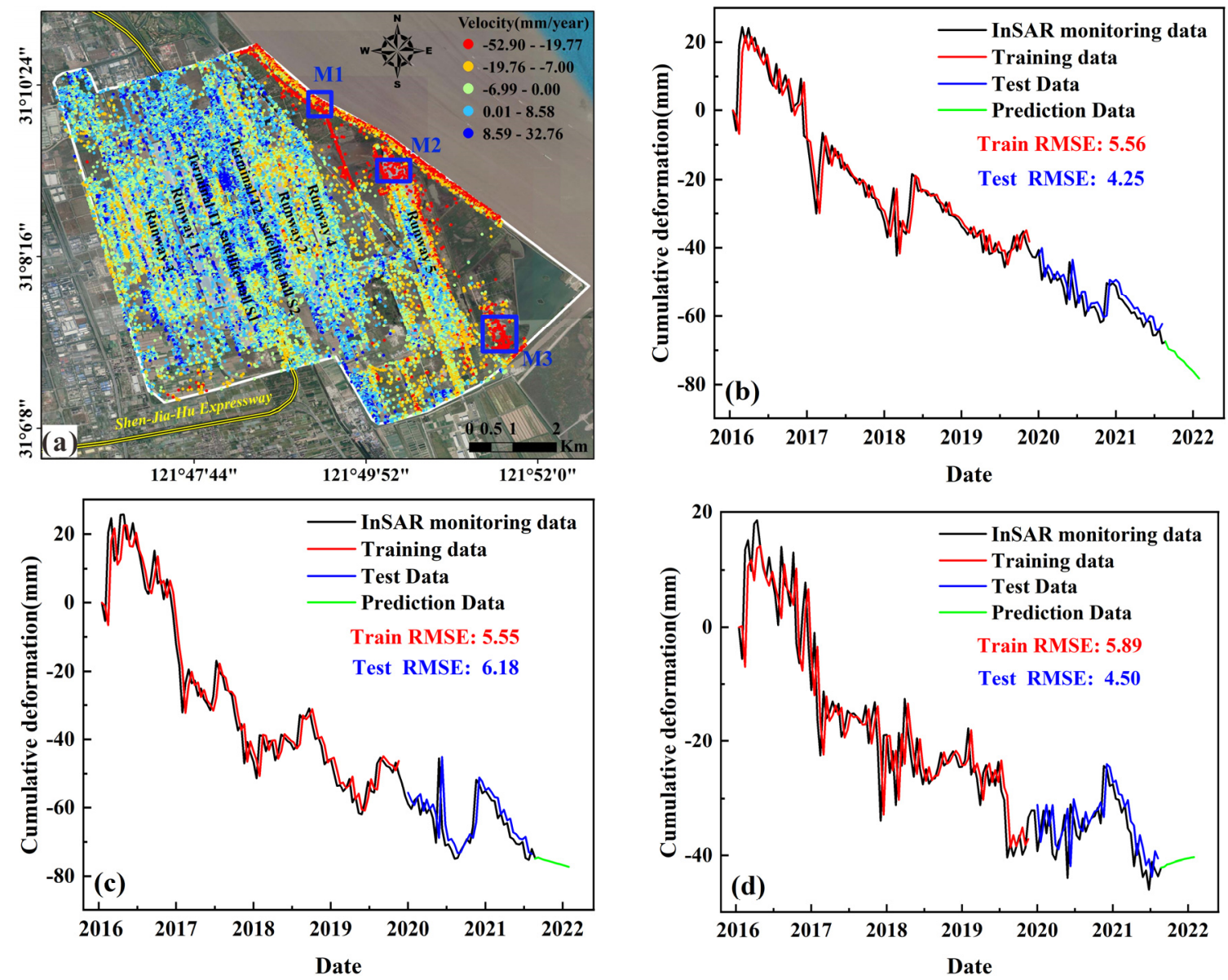

Figure 10. (a) Distribution maps of M1 to M5; cumulative deformation predicted by the LSTM model and monitored by StaMPS PSI in (b) M1, (c) M2, and (d) M3.

It has been shown that primary consolidation, long-term secondary consolidation of alluvial clay deposits beneath the dredge fill, and creep within the dredge fill are considered to be the three mechanisms of ground subsidence in reclaimed areas [47-50]. Subsidence caused by primary consolidation of alluvial clays accounts for most of the overall settlement, even $70 \%$ or more in the airport area [47]. In the SPIA, the reclamation of area D was completed in the second half of 2018. The soil consolidation state in this area is closer to primary consolidation. Therefore, driven by tides or currents, the sediments on the surface of the tidal flats are displaced to different degrees, which seriously affects the ground deformation in area D. 

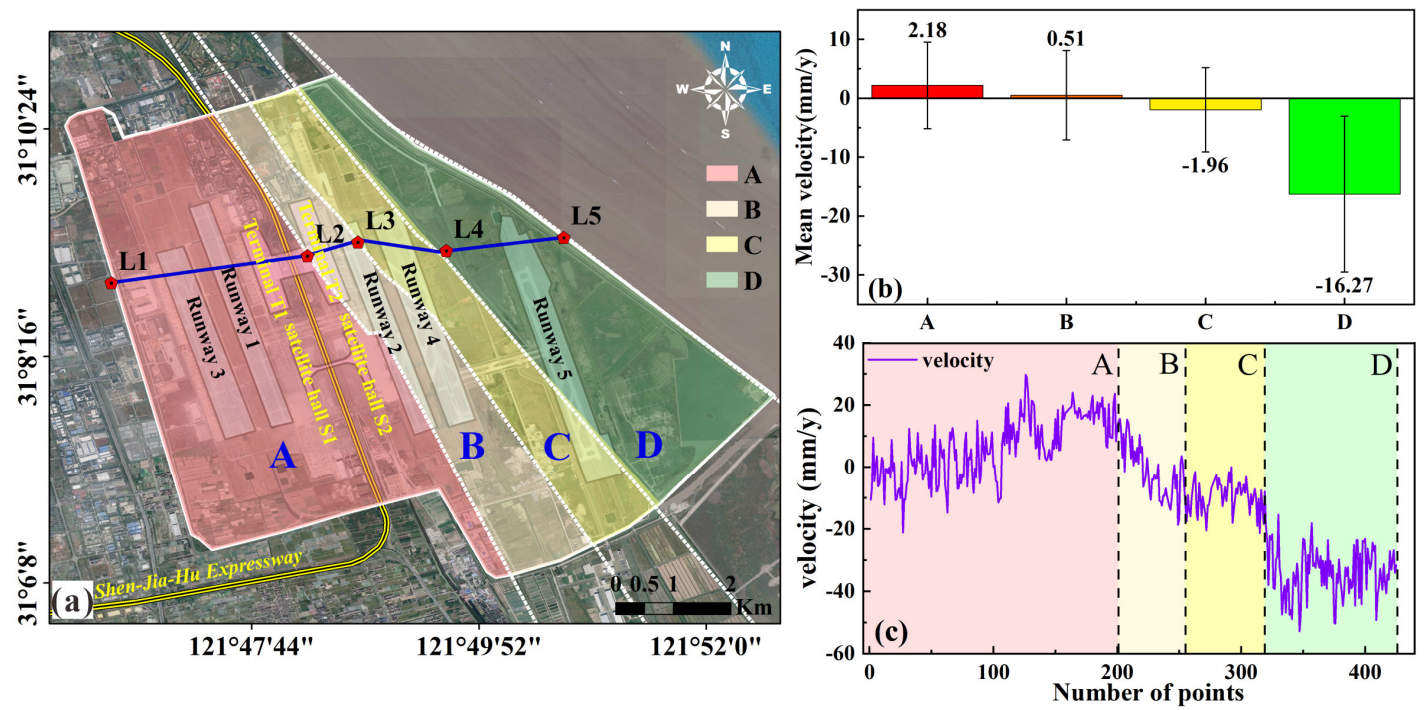

Figure 11. (a) The four zones delineated A, B, C, and D; (b) the average deformation velocity of each zone in 2021; (c) deformation velocity statistics along with L1 to L5 in SPIA in 2021.

Figure 11c shows the ground deformation profile statistics along with L1 to L5 in SPIA from January 1 to September 30, 2021. As shown in Figure 11c, the deformation rate showed an increasing and then decreasing trend from west to east $(\mathrm{L} 1 \rightarrow \mathrm{L} 2 \rightarrow \mathrm{L} 3 \rightarrow \mathrm{L} 4 \rightarrow \mathrm{L} 5)$ within the SPIA, showing consistency with the results observed in Section 4.1.

Figure 12 shows the geological sections from L1 to L3 (i.e., areas A and B). It can be seen that area A was located within the seawall, and the thickness of the shallow soil layer was about 7-10 m. The foundation structure was relatively intact. Area B was obtained from the reclamation project in the late 1990s and was formed shorter than area A. The foundation in area B consisted mainly of blown sand and backfill with the addition of partially backfilled fine-silty sand [6], which, together with the lack of crustal layers, resulted in a relatively weak geological foundation. Area B has undergone more than ten years of soft clay consolidation. According to Terzaghi's theory [51], the rate of ground deformation during the study period should be continuously decreasing [6]. Therefore, the ground deformation in area B gradually stabilized, and this result is consistent with the PSI monitoring results (see Figure 5).

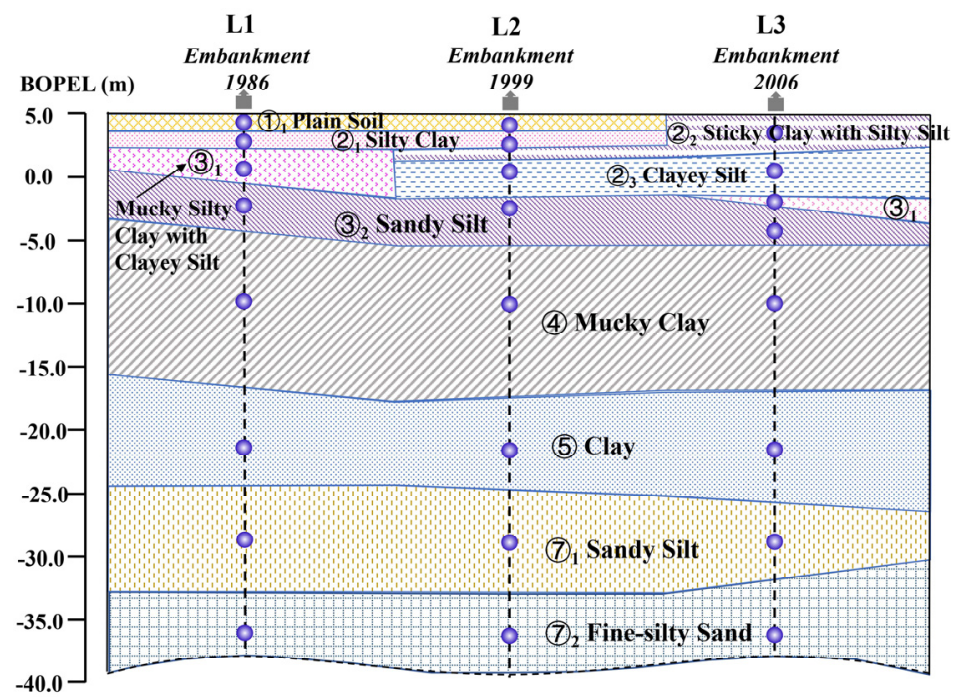

Figure 12. Geological sections from L1 to L3 in SPIA. 


\subsection{SPIA Deformation Pattern Analysis}

The ground changes of SPIA in the three phases after the reclamation project can be inferred based on the ground deformation's spatial distribution and temporal evolution. For newly reclaimed areas, such as areas $C$ and D, soil consolidation will continue for several years, and this primary consolidation is the first phase of change after reclamation. The ground enters a slight rebound after long-term compression when the reclamation has been established for a while, e.g., as area B has been established for more than twenty years, it enters the second phase. Finally, the deformation will remain more stable after long-term changes. The Phase I project of the airport, constructed in 1999, will be completed for at least 22 years by 2021, and the soil has entered into secondary consolidation. The ground deformation should be more stable in theory, such as in area A, where near the commercial and living area, part of the ground deformation is relatively minor. However, as shown in Figure 11c, ground uplift occurred in the eastern part of area A from west to east. In particular, more concentrated uplift occurred close to area B (see Figure 11a). The main reasons for the occurrence of uplift include (1) Topographic errors. The area is characterized by a large number of buildings and infrastructures, especially Terminals T1 and T2 and Satellite Halls S1 and S2, which have unique shapes and complex and diverse structures and are prone to topographic observation errors [6]. (2) The error caused by temperature. Most of the buildings here are made of glass, steel, and concrete, and a Shenjiahu Expressway is running through them. In addition, the main Satellite Halls of the SPIA Phase III expansion project were officially opened on 16 September 2019, so that the whole constitutes a large heat transfer area. As the temperature rises, the buildings experience thermal expansion, which, combined with the unstable soil structure in the area, makes them more susceptible to temperature changes $[52,53]$.

\subsection{Effects of Precipitation and Temperature on Ground Deformation}

Areas C and D in the SPIA are newly reclaimed areas. Since slight and more severe ground subsidence has occurred in these areas, soil consolidation will continue for several years in areas C and D. Significantly, the vital Runway 5 of the airport is located in area D. Therefore, further revealing the ground subsidence mechanism and its effects in these areas is necessary. Previous studies have shown that over-exploitation of groundwater and geological instability are the leading causes of ground subsidence in Shanghai [54-56]. In general, precipitation is positively correlated with groundwater level $[57,58]$. From the analysis in Section 5.3, it is clear that temperature changes also affect the ground deformation. The precipitation and temperature data for 2021 were utilized to discuss their correlation with ground subsidence in 2021 in areas C and D, as SPIA groundwater data were not obtained for the study period. Figure 13a shows the distribution of the observed areas from P1 to P5.

As shown in Figure 13b-d, to quantitatively describe the relationship between precipitation variation and ground subsidence, monthly average precipitation and average cumulative form variables were extracted for gray correlation analysis (GRA) in the area of $\mathrm{P} 1$ to $\mathrm{P} 3$, respectively, in area C. Gray correlation analysis is a method to measure the degree of association between factors. The higher the value of gray correlation, the more similar the trend between factors [59]. From Figure 13b-d, it can be found that the GRA between the mean cumulative form variables and the mean monthly precipitation in areas P1 to P3 were $0.81,0.78$, and 0.77 , respectively, indicating that the trends of ground subsidence and precipitation changes in area $\mathrm{C}$ are in good agreement. From January 1 to February 18, 2021, the period was characterized by low precipitation, while at the same time, ground subsidence occurred in all areas from P1 to P3. With the precipitation increase after February 18,2021 , the ground deformation rate in the three areas decreased and even showed a short time rebound trend. SPIA is on the Quaternary alluvial fan, and the foundation is soft soil. The foundation in area $C$ is mainly composed of silty clay and sandy chalk, with high water content and high compressibility. In addition, there are few buildings and mostly bare land in area C. As a result, when the rainy season arrives, the absorption of 
water from the subsurface soil increases, replenishing groundwater to some extent. With the groundwater level recovery, ground subsidence is alleviated to some extent.
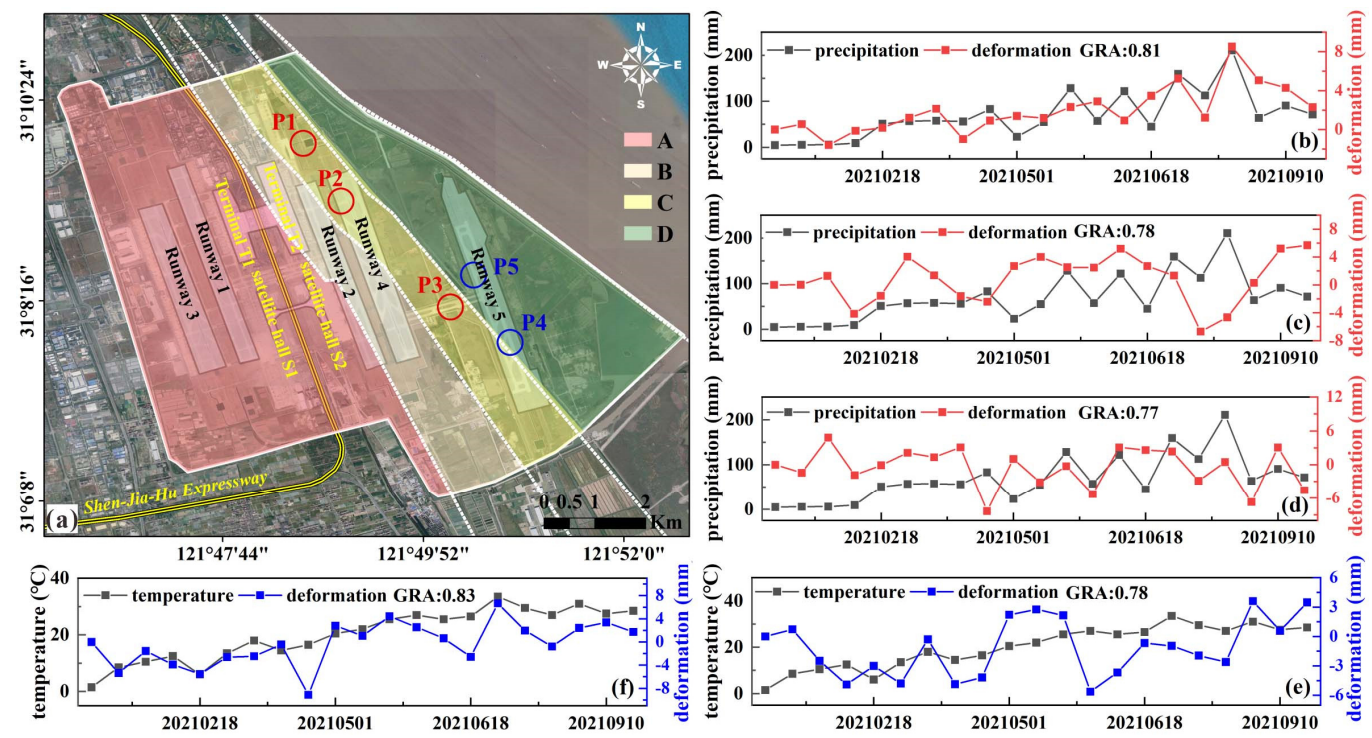

Figure 13. (a) Distribution maps of P1 to P5; the time series of mean deformation cumulative and precipitation in (b) P1, (c) P2, (d) P3; the time series of mean deformation cumulative and temperature in (e) P4, (f) P5.

The areas P4 and P5 are located on Runway 5 of the SPIA. As shown in Figure 13e,f, the GRA between the mean cumulative form variables and the day's mean temperature in areas P4 and P5 were 0.78 and 0.83 , respectively. Such results indicated that ground subsidence in area D is well correlated with the temperature change. The SPIA region was cooler before 1 May 2021, with varying degrees of ground subsidence in areas P4 and P5. The ground subsidence rate slowed down when the temperature rebounded, and the ground even lifted when the temperature continued to rise. This observation also verified the effect of temperature on ground uplift in area A in Section 5.3.

In summary, the ground subsidence in areas $C$ and $D$ showed seasonal variations. In the absence of significant geological alterations or human intervention, ground subsidence in the two areas remains consistent with the trends in precipitation and temperature changes.

\subsection{Recommendations and Strategies for Ground Deformation at Reclamation Airports}

The results of ground deformation based on PSI long time-series observations indicated that ground uplift occurred in the central part of SPIA, while more severe ground subsidence occurred in the eastern part of SPIA. Significant uneven deformation was present throughout the SPIA region (see Figure 5). For reducing the influence of ground deformation on SPIA, this paper proposes a comprehensive prevention and control strategy of uneven ground deformation in SPIA with InSAR monitoring and LSTM prediction as to the major factors and geological environment as to the supplementary factors, respectively.

Firstly, the StaMPS PSI technique was utilized to grasp the SPIA ground deformation and establish a primary ground deformation database for the entire study area. Then, the LSTM prediction model was used to understand the trend of ground deformation in time. The ground deformation mechanism was further analyzed with geological and environmental factors. Corresponding countermeasures were taken according to the four areas of SPIA A, B, C, and D, which are classified in Section 5.2. Finally, the ground deformation database was continuously updated with external multi-source data to form a virtuous SPIA ground deformation monitoring cycle, as shown in Figure 14. The corresponding 
control methods are proposed for four areas for the current situation of SPIA ground inhomogeneous deformation.

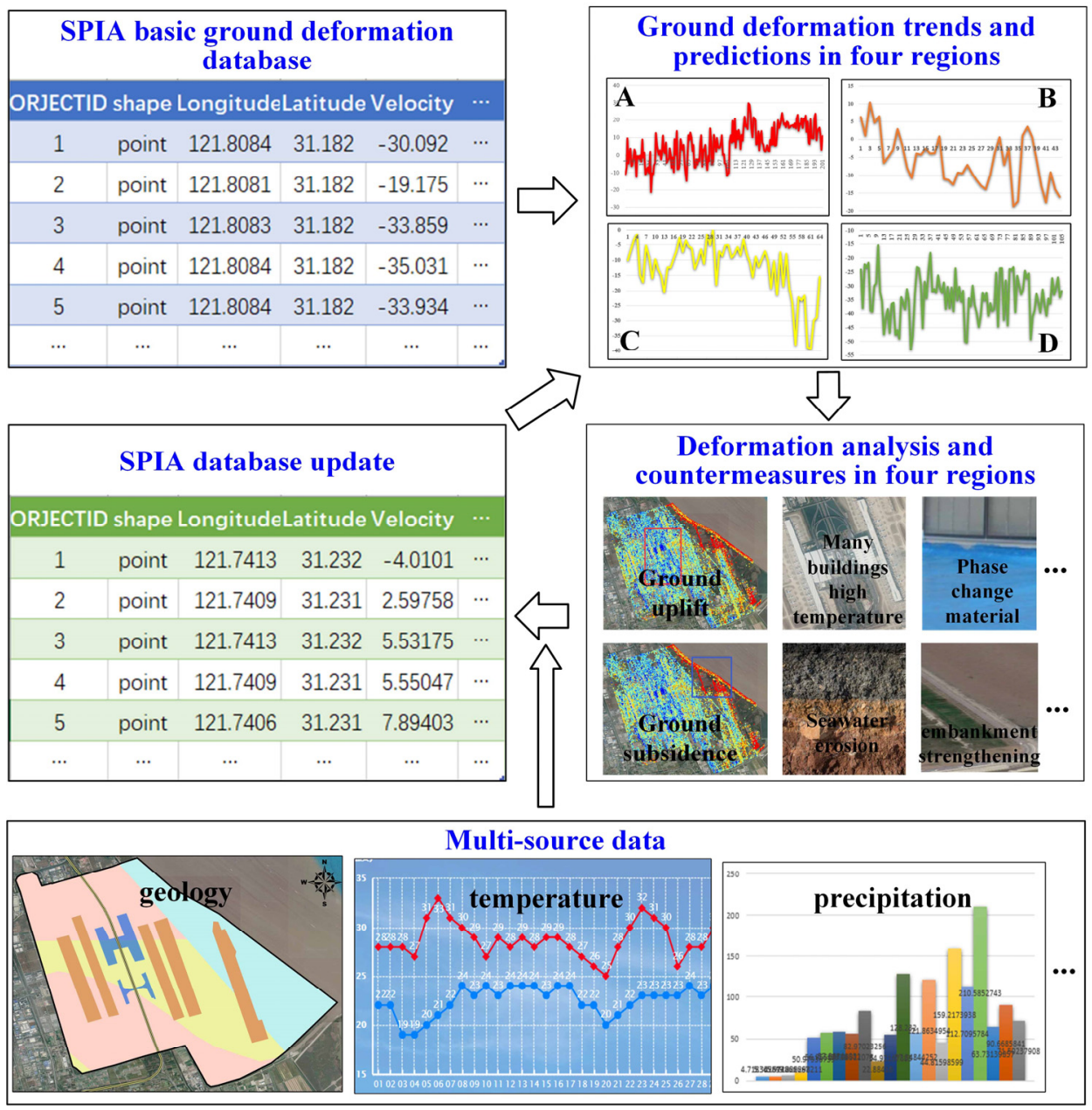

Figure 14. Ground deformation prevention strategies for SPIA, (A-D) are the trends of deformation rates in the four areas.

(1) The available information shows that the foundation of area A was built in 1999. Represented by the western part of this area, the foundation is almost solidified and stable after more than twenty years of sediment consolidation $[7,40]$. Continuous subsidence monitoring is sufficient for this area unless significant geological changes occur.

(2) From the analysis of Section 5.3, it can be seen that ground uplift exists in the eastern part of area A and area B. The causes mainly include both topographic errors and temperature changes. Therefore, high-precision 3D digital topographic maps are necessary to effectively reduce topographic errors when buildings are dense and complex in structure. Alternatively, multi-source data constraint operations can further reduce the impact of human intervention on the results when acquiring ground deformation. For ground deformation caused by temperature changes, unique materials (such as phase change materials) can be integrated into the outer building envelope or road construction process [60] to reduce the impact of surrounding environmental factors on buildings or ground facilities. It has been shown that the deployment of artificial permanent scatterers (corner reflectors) in reclaimed areas can further constrain the ground deformation monitoring results [61]. Therefore, to reduce the influence of decorrelation and environment on the ground deformation monitoring results, corner reflectors can be deployed on the ground with low coherence in the reclamation area, especially in the area near the ocean, which can be encrypted. 
(3) More significant ground subsidence was observed in areas C and D of SPIA. Due to the late reclamation in areas C and D, the foundation geology is weak and less stable [6]. Waves and tides erode the dykes as the sea level rises, causing the revetment to collapse and damage the dykes in severe subsidence areas. Therefore, the polder dykes need to be reinforced, and the height of the coastal seawall needs to be increased. Areas with severe subsidence, such as area D, are worthy of priority attention. Suppose the trend of ground subsidence continues to worsen. In that case, it will be necessary to continue expanding the reclamation area along the coastline and adding a buffer zone to further reduce seawater's impact on geology.

(4) It is recommended to drill holes along the shoreline at each phase according to the reclamation time to obtain more realistic and accurate geological monitoring data, such as the locations of points L1, L2, L3, L4, and L5 in Figure 11a. In addition, it is necessary to conduct some measures such as limiting groundwater withdrawal and increasing groundwater recharge to reduce the ground subsidence.

\section{Conclusions}

In this paper, we carried out the prediction of deformation evolution and subsidence pattern analysis of Shanghai Pudong International Airport based on PSI long time-series observations to disclose the ground deformation evolution characteristics of SPIA reclamation area in recent years. Firstly, the ground deformation results of Shanghai Pudong Reclamation Airport from 6 October 2016 to 22 September 2021 were extracted using Sentinel-1A image data and StaMPS PSI technology. Then, LSTM ground deformation prediction was carried out for areas with severe deformation within SPIA. The joint analysis of historical reclamation projects, geological conditions, precipitation, and temperature were combined to provide a systematic description of the spatial and temporal distribution characteristics and deformation trends of ground deformation in SPIA. Finally, a prevention and control strategy based on InSAR monitoring and LSTM prediction, supplemented by geological and environmental factors, was proposed to utilize the above research results. The main findings are as follows.

(1) Significant and unevenly distributed ground deformation was observed in the SPIA from 2016 to 2021. Severe ground subsidence occurred in the east, with rates ranging from about $-57.29 \mathrm{~mm} / \mathrm{a}$ to $-19.77 \mathrm{~mm} / \mathrm{a}$. Ground uplift occurred in the central and western parts, with a maximum deformation rate of approximately $32.76 \mathrm{~mm} / \mathrm{a}$.

(2) The LSTM ground deformation prediction model displayed excellent robustness, and the RMSEs of the test data were less than 3.52. The prediction results were in high agreement with the monitoring results of StaMPS PSI. In addition, the predictions indicated that there is a risk of large gradient ground deformation in the area close to the coastline during the next six months.

(3) In order of the reclamation construction sequence, we divided the study area into four areas (i.e., areas A, B, C, and D). According to the spatial distribution and temporal evolution characteristics of ground deformation, it can be inferred that SPIA went through three phases after the reclamation project. The primary consolidation phase corresponds to areas $C$ and D. The slight rebound phase corresponds to area $B$. The stabilization phase corresponds to area A.

(4) Based on the gray correlation analysis method, the correlation between ground subsidence and climatic factors was discussed qualitatively and quantitatively for severe subsidence areas. The results showed that the ground subsidence in areas C and D exhibits seasonal variations. The general trend of ground settlement is more consistent with precipitation and temperature changes.

(5) The ground deformation prevention strategy proposed in this paper can be combined with external multi-source data to continuously update the SPIA basic ground deformation database. Through the processing and analysis of data, the ground deformation can be grasped in time for rapid response. 
The method and related results in this paper can be used as a reference for ground deformation monitoring and disaster prevention for other airports in reclaimed areas. In addition, with the exponential growth of external data, the robustness of the prediction model can be improved even further when more data are incorporated into the LSTM model in the future.

Author Contributions: Conceptualization, X.B.; formal analysis, X.B. and R.Z.; funding acquisition, R.Z., G.L.; investigation, A.S., S.L. and L.X.; project administration, J.L. and R.W.; validation, X.B. and Y.F.; writing-original draft, X.B.; writing—review and editing, R.Z. and X.B. All authors have read and agreed to the published version of the manuscript.

Funding: This research was jointly funded by the National Natural Science Foundation of China (Grant 42171355 and 42071410); and the Sichuan Science and Technology Program (No. 2018JY0564, 2019ZDZX0042, 2020JDTD0003 and 2020YJ0322).

Data Availability Statement: The climate data can be downloaded from the website: https:/ /www. ncdc.noaa.gov/cdo-web/ (accessed on 22 December 2021); and the Sentinel-1A SAR images can be downloaded from the website: https://scihub.copernicus.eu/dhus/\#/home (accessed on 22 December 2021).

Acknowledgments: The Sentinel-1A TOPSIW SLCSAR images and the POD data were provided by the Copernicus Sentinel-1 Mission of ESA. We also thank NASA for providing the SRTM DEM data. In addition, we sincerely thank the editors and all anonymous reviewers for their constructive and excellent reviews of our work.

Conflicts of Interest: The authors declare no conflict of interest.

\section{References}

1. Ma, Z.; Melville, D.S.; Liu, J.; Chen, Y.; Yang, H.; Ren, W.; Zhang, Z.; Piersma, T.; Li, B. Rethinking China's new great wall. Science 2014, 346, 912-914. [CrossRef] [PubMed]

2. Sengupta, D.; Chen, R.; Meadows, M.E. Building beyond land: An overview of coastal land reclamation in 16 global megacities. Appl. Geogr. 2018, 90, 229-238. [CrossRef]

3. Martín Antón, M.; Negro, V.; del Campo, J.M.; López-Gutiérrez, J.S.; Esteban, M.D. Review of coastal land reclamation situation in the world. J. Coast. Res. 2016, 667-671. [CrossRef]

4. Wu, S.; Yang, Z.; Ding, X.; Zhang, B.; Zhang, L.; Lu, Z. Two decades of settlement of hong kong international airport measured with multi-temporal InSAR. Remote Sens. Environ. 2020, 248, 111976. [CrossRef]

5. Sheng, N.; Tang, U.W.; Grydehøj, A. Urban morphology and urban fragmentation in Macau, China: Island city development in the Pearl River Delta megacity region. Isl. Stod. J. 2017, 12, 199-212. [CrossRef]

6. Jiang, Y.; Liao, M.; Wang, H.; Zhang, L.; Balz, T. Deformation monitoring and analysis of the geological environment of Pudong international airport with persistent scatterer SAR interferometry. Remote Sens. 2016, 8, 1021. [CrossRef]

7. Yu, L.; Yang, T.; Zhao, Q.; Pepe, A.; Dong, H.; Sun, Z. Residual settlements detection of ocean reclaimed lands with multi-platform SAR time series and SBAS technique: A case study of Shanghai Pudong International Airport. In Proceedings of the Remote Sensing and Modeling of Ecosystems for Sustainability XIV, San Diego, CA, USA, 1 September 2017; p. 104050X.

8. Zheng, L.; Zhu, L.; Wang, W.; Guo, L.; Chen, B. Land subsidence related to coal mining in China revealed by L-band InSAR analysis. Int. J. Environ. Res. Public Health 2020, 17, 1170. [CrossRef]

9. Xiang, W.; Zhang, R.; Liu, G.; Wang, X.; Mao, W.; Zhang, B.; Fu, Y.; Wu, T. Saline-Soil Deformation Extraction Based on an Improved Time-Series InSAR Approach. ISPRS Int. J. Geo-Inf. 2021, 10, 112. [CrossRef]

10. Liu, G.; Jia, H.; Zhang, R.; Zhang, H.; Jia, H.; Yu, B.; Sang, M. Exploration of subsidence estimation by persistent scatterer InSAR on time series of high resolution TerraSAR-X images. IEEE J. Sel. Top. Appl. Earth Obs. Remote Sens. 2010, 4, 159-170. [CrossRef]

11. Xue, F.; Lv, X.; Chai, H.; Huang, H. Application of particle swarm optimization to the estimation of the TSInSAR deformation parameter. Remote Sens. Lett. 2019, 10, 756-765. [CrossRef]

12. Karamvasis, K.; Karathanassi, V. Performance Analysis of Open Source Time Series InSAR Methods for Deformation Monitoring over a Broader Mining Region. Remote Sens. 2020, 12, 1380. [CrossRef]

13. Liu, G.; Jia, H.; Nie, Y.; Li, T.; Zhang, R.; Yu, B.; Li, Z. Detecting subsidence in coastal areas by ultrashort-baseline TCPInSAR on the time series of high-resolution TerraSAR-X images. IEEE Trans. Geosci. Remote Sens. 2013, 52, 1911-1923. [CrossRef]

14. Hooper, A.; Zebker, H.; Segall, P.; Kampes, B. A new method for measuring deformation on volcanoes and other natural terrains using InSAR persistent scatterers. Geophys. Res. Lett. 2004, 31, L23611. [CrossRef]

15. Hooper, A.; Bekaert, D.; Spaans, K.; Arıkan, M. Recent advances in SAR interferometry time series analysis for measuring crustal deformation. Tectonophysics 2012, 514, 1-13. [CrossRef] 
16. Ma, G.; Zhao, Q.; Wang, Q.; Liu, M. On the effects of InSAR temporal decorrelation and its implications for land cover classification: The case of the ocean-reclaimed lands of the Shanghai megacity. Sensors 2018, 18, 2939. [CrossRef]

17. Qiao, G.; Mi, H.; Wang, W.; Tong, X.; Li, Z.; Li, T.; Liu, S.; Hong, Y. 55-year (1960-2015) spatiotemporal shoreline change analysis using historical DISP and Landsat time series data in Shanghai. Int. J. Appl. Earth Obs. Geoinf. 2018, 68, 238-251. [CrossRef]

18. Miao, L.; Deng, K.; Feng, G.; Li, K.; Xiong, Z.; Wang, Y.; He, S. Reclaimed-Airport Surface-Deformation Monitoring by Improved Permanent-Scatterer Interferometric Synthetic-Aperture Radar: A Case Study of Shenzhen Bao'an International Airport, China. Photogramm. Eng. Remote Sens. 2021, 87, 105-116. [CrossRef]

19. Zhao, Q.; Lin, H.; Gao, W.; Zebker, H.A.; Chen, A.; Yeung, K. InSAR detection of residual settlement of an ocean reclamation engineering project: A case study of Hong Kong International Airport. J. Oceanogr. 2011, 67, 415-426. [CrossRef]

20. Pitcher, L.H.; Smith, L.C.; Gleason, C.J.; Yang, K. CryoSheds: A GIS modeling framework for delineating land-ice watersheds for the Greenland ice sheet. GISci. Remote Sens. 2016, 53, 707-722. [CrossRef]

21. Ye, S.; Luo, Y.; Wu, J.; Yan, X.; Wang, H.; Jiao, X.; Teatini, P. Three-dimensional numerical modeling of land subsidence in Shanghai, China. Hydrol. J. 2016, 24, 695-709. [CrossRef]

22. Li, Y.; Zuo, X.; Ma, Y.; Xiong, P.; Yany, F. Surface subsidence monitoring and prediction based on PS-InSAR technology and genetic neural network algorithm. Prog. Geophys. 2020, 35, 845-851.

23. Chen, Y.; He, Y.; Zhang, L.; Chen, Y.; Pu, H.; Chen, B.; Gao, L. Prediction of InSAR deformation time-series using a long short-term memory neural network. Int. J. Remote Sens. 2021, 42, 6919-6942. [CrossRef]

24. Ding, Q.; Shao, Z.; Huang, X.; Altan, O.; Zhuang, Q.; Hu, B. Monitoring, analyzing and predicting urban surface subsidence: A case study of Wuhan City, China. Int. J. Appl. Earth Obs. Geoinf. 2021, 102, 102422. [CrossRef]

25. Liu, Q.; Zhang, Y.; Deng, M.; Wu, H.; Kang, Y.; Wei, J. Time series prediction method of large-scale surface subsidence based on deep learning. Acta Geod. Cartogr. Sin. 2021, 50, 396-404.

26. Wang, S. Analysis of Financial Statements-Shanghai Airport as an Example. Ind. Technol. Forum 2021, $20,82-83$.

27. The Silver Gull Spreads Its Wings, the Blue Sky Is Connected with the Yellow earth, and the Scenery and Services Are Beautiful Together. Available online: http://shanghai.xinmin.cn/msrx/2017/09/10/31271572.html (accessed on 10 January 2022).

28. Deciphering the "Code" of Pudong Airport II. Available online: http://news.sina.com.cn/c/2006-01-18/11308902649.shtml (accessed on 10 January 2022).

29. Wang, R.; Yang, T.; Yang, M.; Liao, M.; Lin, J.; Zhang, L. Attribution Analysis on Deformation Feature of the ShanghaiElevated Highway by Persistent Scatterer SAR Interferometry. Geomat. Inf. Sci. Wuhan Univ. 2018, 43, 2050-2057.

30. Hooper, A. Persistent scatterer InSAR for crustal deformation analysis, with application to Volcán Alcedo, Galápagos. J. Geophys. Res. B 2007, 112, 1-19. [CrossRef]

31. Sun, H.; Zhang, Q.; Zhao, C.; Yang, C.; Sun, Q.; Chen, W. Monitoring land subsidence in the southern part of the lower Liaohe plain, China with a multi-track PS-InSAR technique. Remote Sens. Environ. 2017, 188, 73-84. [CrossRef]

32. Ferretti, A.; Prati, C.; Rocca, F. Permanent scatterers in SAR interferometry. IEEE Trans. Geosci. Remote Sens. 2001, 39, 8-20. [CrossRef]

33. Dwivedi, R.; Varshney, P.; Tiwari, A.; Narayan, A.B.; Singh, A.K.; Dikshit, O.; Pallav, K. Monitoring of landslides in Nainital, Uttarakhand, India: Validation of PS-InSAR results. In Proceedings of the 2015 Joint Urban Remote Sensing Event (JURSE), Lausanne, Switzerland, 30 March-1 April 2015; pp. 1-4.

34. Wei, L.; Guan, L.; Qu, L.; Guo, D. Prediction of Sea Surface Temperature in the China Seas Based on Long Short-Term Memory Neural Networks. Remote Sens. 2020, 12, 2697. [CrossRef]

35. Yuan, Q.; Shen, H.; Li, T.; Li, Z.; Li, S.; Jiang, Y.; Xu, H.; Tan, W.; Yang, Q.; Wang, J. Deep learning in environmental remote sensing: Achievements and challenges. Remote Sens. Environ. 2020, 241, 111716. [CrossRef]

36. Liu, Q.; Zhang, Y.; Wei, J.; Wu, H.; Deng, M. HLSTM: Heterogeneous Long Short-Term Memory Network for Large-Scale InSAR Ground Subsidence Prediction. IEEE J. Sel. Top. Appl. Earth Obs. Remote Sens. 2021, 14, 8679-8688. [CrossRef]

37. Hochreiter, S.; Schmidhuber, J. Long short-term memory. Neural Comput. 1997, 9, 1735-1780. [CrossRef] [PubMed]

38. Yang, M.; Yang, T.; Zhang, L.; Lin, J.; Qin, X.; Liao, M. Spatio-temporal characterization of a reclamation settlement in the Shanghai coastal area with time series analyses of X-, C-, and L-band SAR datasets. Remote Sens. 2018, 10, 329. [CrossRef]

39. Schmidt, D.A.; Bürgmann, R. Time-dependent land uplift and subsidence in the Santa Clara valley, California, from a large interferometric synthetic aperture radar data set. J. Geophys. Res. Solid Earth 2003, 108. [CrossRef]

40. Yu, L.; Yang, T.; Zhao, Q.; Liu, M.; Pepe, A. The 2015-2016 ground displacements of the Shanghai coastal area inferred from a combined COSMO-SkyMed/Sentinel-1 DInSAR analysis. Remote Sens. 2017, 9, 1194. [CrossRef]

41. Liu, D. Settlement Deformation Characteristics of Soft Soil and Its Control Measures of the Four Runway of Pudong Airport. Ph.D. Thesis, China University of Mining \& Technology, Beijing, China, 2018.

42. Kingma, D.P.; Ba, J. Adam: A method for stochastic optimization. arXiv 2014, arXiv:1412.6980.

43. Chai, J.C.; Shen, S.L.; Zhu, H.H.; Zhang, X.L. 1D analysis of land subsidence in Shanghai. Lowl. Technol. Int. 2005, 7, 33-41.

44. Hong, Z.S.; Zeng, L.L.; Cui, Y.J.; Cai, Y.Q.; Lin, C. Compression behaviour of natural and reconstituted clays. Géotechnique 2012, 62, 291-301. [CrossRef]

45. Stamatopoulos, C.; Petridis, P.; Parcharidis, I.; Foumelis, M. A method predicting pumping-induced ground settlement using back-analysis and its application in the Karla region of Greece. Nat. Hazards 2018, 92, 1733-1762. [CrossRef] 
46. Ortiz-Zamora, D.; Ortega-Guerrero, A. Evolution of long-term land subsidence near Mexico City: Review, field investigations, and predictive simulations. Water Resour. Res. 2010, 46. [CrossRef]

47. Lanari, R.; Berardino, P.; Bonano, M.; Casu, F.; Manconi, A.; Manunta, M.; Manzo, M.; Pepe, A.; Pepe, S.; Sansosti, E. Surface displacements associated with the L'Aquila $2009 \mathrm{Mw} 6.3$ earthquake (central Italy): New evidence from SBAS-DInSAR time series analysis. Geophys. Res. Lett. 2010, 37. [CrossRef]

48. Al-Barwani, H.; Purnama, A. Re-assessing the impact of desalination plants brine discharges on eroding beaches. Desalination 2007, 204, 94-101. [CrossRef]

49. Douglas, I.; Lawson, N. Airport construction: Materials use and geomorphic change. J. Air Transp. Manag. 2003, 9, 177-185. [CrossRef]

50. Shen, S. Geological environmental character of Lin-Gang new city and its influences to the construction. Shanghai Geol. $2008,1$.

51. Terzaghi, K.; Peck, R.B.; Mesri, G. Soil Mechanics in Engineering Practice; John Wiley \& Sons: Hoboken, NJ, USA, 1996.

52. Crosetto, M.; Monserrat, O.; Cuevas-González, M.; Devanthéry, N.; Crippa, B. Analysis of X-Band Very High Resolution Persistent Scatterer Interferometry Data Over Urban Areas. In Proceedings of the ISPRS-International Archives of the Photogrammetry, Remote Sensing and Spatial Information Sciences, Hannover, Germany, 1-24 May 2013; pp. 21-24.

53. Crosetto, M.; Monserrat, O.; Cuevas-González, M.; Devanthéry, N.; Luzi, G.; Crippa, B. Measuring thermal expansion using X-band persistent scatterer interferometry. ISPRS J. Photogramm. Remote Sens. 2015, 100, 84-91. [CrossRef]

54. Chen, J.; Wu, J.; Zhang, L.; Zou, J.; Liu, G.; Zhang, R.; Yu, B. Deformation trend extraction based on multi-temporal InSAR in Shanghai. Remote Sens. 2013, 5, 1774-1786. [CrossRef]

55. Wang, H. The Risk Assessment System and RiskManagement of Land Subsidence in Shanghai. Ph.D. Thesis, Shanghai University, Shanghai, China, 2013.

56. Yue, L.; Shujun, Y.; Jichun, W.; Xun, J.; Hanmei, W. Characterization of land subsidence during recovery of groundwater levels in Shanghai. Geol. J. China Univ. 2015, 21, 243.

57. Lorenzo-Lacruz, J.; Garcia, C.; Morán-Tejeda, E. Groundwater level responses to precipitation variability in Mediterranean insular aquifers. J. Hydrol. 2017, 552, 516-531. [CrossRef]

58. Qi, P.; Zhang, G.; Xu, Y.J.; Wang, L.; Ding, C.; Cheng, C. Assessing the influence of precipitation on shallow groundwater table response using a combination of singular value decomposition and cross-wavelet approaches. Water 2018, 10, 598. [CrossRef]

59. Yi, P.; Dong, Q.; Li, W.; Wang, L. Measurement of city sustainability based on the grey relational analysis: The case of 15 subprovincial cities in China. Sustain. Cities Soc. 2021, 73, 103143. [CrossRef]

60. Kishore, R.A.; Bianchi, M.V.; Booten, C.; Vidal, J.; Jackson, R. Enhancing building energy performance by effectively using phase change material and dynamic insulation in walls. Appl. Energy 2021, 283, 116306. [CrossRef]

61. Qin, Y.; Perissin, D. Monitoring ground subsidence in Hong Kong via spaceborne Radar: Experiments and validation. Remote Sens. 2015, 7, 10715-10736. [CrossRef] 